\title{
A ISLAMOFOBIA PRIVADA DE HOLLYWOOD:UMA ANÁLISE DO LIVRO AMERICAN ISLAMOPHOBIA: UNDERSTANDING THE ROOTS AND RISE OF FEAR.
}

\author{
Bruno Tadeu Novato Resende ${ }^{1}$ \\ KHALED A. BEYDOUN \\ Oakland: University of California Press, 2018 \\ 264 páginas
}

No livro American Islamophobia: Understanding the Roots and Rise of Fear, o professor universitário especialista em direito constitucional e direitos civis, Khaled Beydoun, apresenta aos leitores a estrutura política que permitiu que a islamofobia prosperasse no imaginário social norte-americano. Na presente resenha apresentarei aos leitores como os filmes americanos reproduzem várias das estereotipias denunciadas por Beydoun tendo como premissa alguns conceitos da história política e cultural.

Khaled Beydoun é um dos principais pensadores da atualidade no que concerne à islamofobia. Conta com publicações relevantes também em outros temas, como segurança nacional, segurança cibernética e direitos civis. 0 autor já publicou uma série de livros, sendo American islamophobia o seu trabalho de maior impacto, e apresentou suas ideias em jornais de grande circulação nos Estados Unidos, como The New York Times e The Washington Post, e nas principais revistas acadêmicas de direito do país. Atualmente atua como professor na escola de direito da Universidade do Arkansas e é professor sênior na faculdade da Califórnia, em Berkeley.

Na epígrafe, Beydoun apresenta aos leitores uma citação de Edward Said evidenciando qual será a tônica metodológica utilizada em American Islamophobia.

0 trecho escolhido apresenta como Said, ao escrever o Orientalismo, pretendia conferir uma resposta de um oriental aos orientalistas, os quais haviam prosperado por muito tempo graças ao silêncio dos orientais. De forma similar ao trabalho de Said, Beydoun afirma que pretende oferecer uma resposta aos estereótipos estabelecidos por um grupo

\footnotetext{
1 É doutorando do programa de pós-graduação em história da Universidade Federal do Rio Grande do Sul e tem interesse na área de Ásia e África, assim como em suas confluências culturais nos Estados Unidos, por meio de fontes midiáticas impressas e audiovisuais. Link para o Currículo Lattes: http://lattes.cnpq. br/0937068258533157. ORCID: https://orcid.org/0000-0001-5012-8713. Contato: bruno_tnr@hotmail. com
} 
social hegemônico sobre outro minoritário nos Estados Unidos da América.

$\mathrm{Na}$ introdução, o autor apresenta o impacto social dos atentados de 11 de setembro de 2001 sobre ele, sua família e sobre a comunidade muçulmana americana, visto que os perpetradores do ataque eram do mesmo grupo social que eles. 0 medo da reação odiosa, que aconteceria nos meses posteriores, se tornou um traço preponderante da corda bamba existencial que caracteriza a identidade muçulmana daquela data até a atualidade. Para Beydoun, essa sensação de medo, galvanizada pelo Estado americano através de políticas danosas à comunidade muçulmana e ao Islã, seria a melhor forma de exprimir a concepção de islamofobia.

Segundo o autor, esse sistema que incutiu medo e intolerância na população não surgiu em 11 de setembro, sendo uma forma profunda de ódio americano existente há vários séculos. Os atentados de 2001 apenas contribuíram para que esse preceito aparecesse com políticas mais agressivas e de forma institucionalizada sob o auspício da "Guerra ao terror".

Ao consideraremos a respeito da proposição de Beydoun, sobre a existência de um ódio secular contra os muçulmanos e ao islã, nos questionamos qual o papel da mídia na reprodução e no endosso desse imaginário negativo. Para entendermos como a mídia contribui com a divulgação dos estereótipos previamente estabelecidos dentro de uma determinada sociedade precisamos, inicialmente, compreender dois conceitos fundamentais da História cultural: o conceito de imaginário social e o conceito de representação.

Segundo Bronislaw Baczko (1985) o imaginário social é um substrato ideológico criado de forma coletiva e mantido por uma comunidade. Esse substrato é responsável por modelar condutas, visões de mundo e modos de sociabilidade que podem endossar a ordem vigente ou servir como elemento contestador. A partir dessa perspectiva, o imaginário social aparece como responsável pela elaboração das representações e das caricaturas em um dado contexto histórico e social.

Com respeito ao conceito de "Representação", Chartier (1990, p. 17) elucida que a terminologia se exemplifica por meio de classificações, divisões e delimitações que organizam apreensões do mundo social como categorias de percepção do mundo real. Essas categorias sempre buscam universalizar os interesses dos grupos que as forjaram através de práticas políticas, sociais e escolares que impõem uma autoridade a custo do menosprezo de outros grupos sociais.

0 imaginário de uma determinada sociedade pode ser identificado e explorado através de diversas fontes históricas. Nessa resenha escolhemos o cinema de ficção, dado que segundo Lagny $(2009,102$ - 105), por se alimentar mais dos modelos de "longa-duração" do que das inovações, esse objeto histórico é bastante produtivo no que se refere à análise das representações de uma determinada sociedade. De acordo com essa premissa, apresentaremos uma análise de um conjunto de filmes com o propósito de verificar se o pressuposto de Beydoun, a qual islamofobia existe nos Estados Unidos há vários séculos, aparece de forma latente no cinema. Começaremos analisando algumas produções anteriores aos atentados de 11 de setembro.

No filme Back To the Future (1985) [De volta pro Futuro], com lucro estimado em 210 milhões de dólares nos Estados Unidos e mais de 178 milhões no resto do mundo, 
uma guerrilha de origem líbia e de inspiração muçulmana pretende construir e detonar uma bomba nuclear em território americano sem nenhuma razão consistente. A presença de uma milícia muçulmana em uma cidade fictícia de pequeno porte da Califórnia em um filme cujo objetivo é explorar o passado de uma família problemática, através de uma viagem no tempo, é totalmente deslocada da narrativa. Demonstra ainda a existência de um imaginário e de um conjunto de referentes que representam os muçulmanos como naturalmente maus e violentos, já que a presença deles ali é absurda e totalmente irrelevante para a trama.

O filme The Siege (1998) [Nova York Sitiada], com faturamento acima dos $40 \mathrm{mi}$ lhões de dólares nos Estados Unidos e 70 milhões no resto do mundo, apresenta aos espectadores a missão de um agente do FBI, de uma agente da Cia e de um general norte-americano para impedir que um grupo terrorista detone uma série de explosivos espalhados pela cidade de Nova York. Embora procure caracterizar alguns personagens árabes de forma positiva, o filme apresenta à audiência os terroristas como muçulmanos violentos e mártires aptos a se sacrificar por uma causa controversa e frívola, porquanto a ameaça à bomba se deve a prisão de um líder religioso.

No capítulo um, o autor se aprofunda na definição do termo islamofobia retomando o assassinato de três jovens muçulmanos americanos na Carolina do Norte, que ele ressalta como coração sul do país e, consequentemente, mais adepta da vilanização do islã promovida pela emissora de televisão Fox News. Ao citar a frase de Yusor Abu-Salha para seu pai antes de ser assassinada, "eu acho que isso é pela maneira como nos parecemos e nos vestimos", Beydoun evidencia que os Hicks ${ }^{2}$ da vizinhança de Yusor e dos outros jovens assassinados não os enxergavam como estudantes americanos, mas como Outsiders, como uma comunidade a parte que não compartilhava do mesmo imaginário social deles, uma vez que suas visões de mundo e memórias afetivas não eram as mesmas (BACZKO, 1980).

0 autor entende que o aforismo islamofobia se explicita por meio de uma estrutura que pressupõe o islã como inerentemente violento, alienado e inassimilável. Essa presunção parte da crença que a identidade muçulmana é correlata com uma propensão ao terrorismo. Em outras palavras, Beydoun caracteriza a islamofobia como uma progênie do orientalismo, um ideário que coloca o islã como antagonista do ocidente e que foi construído embasado em estereotipias do imaginário orientalista formado durante as incursões dos europeus à Ásia.

0 autor desdobra o conceito em três vertentes principais: a islamofobia privada, a islamofobia estrutural e a islamofobia dialética. No que se refere à islamofobia privada, Beydoun demonstra que se trata de uma corrente em que a islamofobia é praticada por atores que não possuem laços com o Estado, como instituições privadas, redes de televisão e o cinema.

A islamofobia estrutural se explicita através da institucionalização de práticas discriminatórias e da promulgação de leis por parte dos atores governamentais com intuito de associar a identidade islâmica a uma ameaça à segurança nacional. Essa forma de islamofobia se ancora sobretudo no imaginário orientalista. A guerra ao terror, iniciada pelo

\footnotetext{
${ }^{2}$ Termo utilizado para designar sulistas interioranos. Um termo aproximado em português seria caipira.
} 
presidente George Bush, seria o expoente mais evidente dessa corrente.

A terceira e última vertente, a islamofobia dialética, é a menos detectável por ser o fio que amarra as outras duas tendências. De modo geral, o autor demonstra que o entendimento dessa corrente perpassa pela compreensão de como a islamofobia estrutural se modela, se remodela e endossa pontos de vista ou atitudes concernentes ao Islã e aos muçulmanos dentro e fora das fronteiras norte-americanas.

O filme Cast a Giant Shadow (1960) [À Sombra de um Gigante], apresenta cada uma dessas correntes descritas por Beydoun, visto que ao retratar o conflito árabe-israelense, essencializa e desumaniza todos os árabes como psicopatas violentos através de estereótipos orientalistas. 0 mais evidente deles aparece na caracterização dos insurgentes árabes e palestinos de forma similar aos povos beduínos do norte da África, ainda que esses povos que viviam no Oriente Médio na época da produção se vestissem de maneira totalmente diferente.

A cena que demonstra a desumanização de maneira mais axiomática se dá através da representação completamente descabida e despropositada de uma vítima da insurgência. De modo dramático, o filme apresenta uma mulher amarrada a um ônibus, com seu tronco nu e uma estrela de Davi desenhada em suas costas. Fica explícito como a película retrata os radicais como grotescos e naturalmente malvados, sem nenhuma causa razoável que permita ao espectador fazer uma reflexão mais profunda sobre o problema político da região.

Essa cena também demonstra que as demandas justas dos palestinos e a complexidade cultural inerente a um grupo social diverso como é o caso dos árabes não fazem parte do imaginário norte-americano construído através dos séculos. A existência de uma considerável parcela cristã é totalmente ignorada e as diferenças regionais entre os povos do Oriente Médio e da África, no que se refere as tradições e costumes, são amalgamadas visando atribuir aos antagonistas um traço de exotismo.

No Capítulo dois, Beydoun inicia suas considerações sobre as raízes da islamofobia moderna com uma citação do ex-presidente Donald Trump de 2016, na qual o então candidato alega acreditar que o islã odiava todos os americanos. A partir dessa proposição, o autor retoma a decisão das cortes de justiça de não conferir cidadania americana aos muçulmanos entre os anos de 1794 a 1944, com intuito de explanar a razão do sentimento anti-muçulmano que existe no país e de demonstrar que não se tratava de um fenômeno recente.

Segundo Beydoun, os muçulmanos sempre foram indesejados, inassimiláveis e demonizados como grupo através da história americana. A campanha anti-imigração e pela expulsão dos islamitas dos Estados Unidos, promovida por Donald Trump durante a corrida presidencial de 2016, apenas mobilizava e ressignificava um sentimento anti-islâmico, fortemente fundamentado em estereótipos, enraziados no país há vários séculos.

0 autor evidencia que, da mesma forma que houve uma racialização dos negros como sinônimo de escravidão e propriedade, o islamismo passou a ser sinônimo de identidade exclusiva dos povos árabes e oriundos do Oriente Médio. Um negro muçulmano, por exemplo, era uma contradição jurídica. Ao citar Edward Said, Beydoun evidencia que a vilanização do islã faz parte do processo de definição da identidade branca europeia através de um processo que ele caracteriza como de identidade espelhada, isto é, a Europa 
como antítese do Oriente. Os políticos responsáveis pela construção das bases políticas e jurídicas dos Estados Unidos, logo após a independência, compreendiam o islã como uma antítese da verdadeira fé protestante e que, por essa razão, não deveria ser incentivado.

O filme infantil Aladdin (1992), da Disney, apresenta aos espectadores como o imaginário orientalista está profundamente enraizado na sociedade americana. Fica evidente, logo nas primeiras cenas, que o protagonista Aladdin e a princesa Jasmine, seu par romântico, não são representados de maneira caricatural como o resto dos personagens humanos que têm um sotaque carregado. Essa escolha da direção apresenta uma preocupação em conferir humanidade e empatia aos protagonistas, diferentemente dos guardas e dos habitantes do país fictício de Agrabah.

A película apresenta ainda uma sequência na qual, após Aladdin performar uma canção que sua terra é um local bárbaro e violento em que você pode acabar perdendo uma orelha, a princesa Jasmine quase tem a mão cortada por dar uma maçã para uma criança pobre e faminta. As representações demonstram aos espectadores de forma bastante explícita como a violência é naturalizada pelos orientais, como se eles vivessem de acordo com as normas de quinhentos anos atrás, um claro contraste com o modo de vida ocidental.

Embora as hipóteses de Beydoun encontrem eco no imaginário norte-americano, como os filmes apresentados evidenciam, não podemos deixar de notar como o autor se utiliza do termo islamofobia de forma fluída. Apesar de considerar que essa prática foi estabelecida há vários séculos, Beydoun se apropria do conceito de orientalismo, buscando explicar o processo de fundação dos Estados Unidos sob bases cristãs, e não distingue, de maneira evidente, esse pressuposto da islamofobia. Ou seja, malgrado o autor pontue que o orientalismo é o predecessor do ódio ao islã, as balizas dos conceitos acabam por se confundir.

Ao trabalharmos com a História, é imprescindível que nos atentemos para o risco do imperativo do presente, uma vez que assim como evidencia Adam Schaff o presentismo relativiza os fatos históricos e "[...] considera a história como uma projeção do pensamento e dos interesses presentes sobre o passado" $(1995,101)$.

No capítulo três, Beydoun dá início as suas considerações propondo um debate sobre um novo clash de civilizações recorrendo ao estudioso que popularizou o termo, Samuel Huntington. Segundo Huntington, é impossível amarmos o que somos se não odiássemos o que não somos, assim como é impossível ter amigos verdadeiros sem inimigos verdadeiros. Sobre esse excerto o autor demonstra que, embora dos anos 1980 pra cá a grande maioria dos ataques terroristas tenha sido perpetrada por homens brancos cristãos, os muçulmanos sempre foram o alvo preferencial não só dos nacionalistas reacionários, como também da grande imprensa.

Beydoun reitera que, utilizando as premissas do conceito de clash de civilizações, pretende explorar o período anterior ao surgimento da islamofobia moderna: o período anterior ao 11 de setembro de 2001. De acordo com o autor, a política de segurança nacional empregada pelos Estados Unidos, baseada fortemente na teoria de Samuel Hutington, revitalizou e reempregou os estereótipos enraizados no orientalismo que, ao serem apropriados pela grande mídia, contribuíram muito mais para uma guerra contra os muçulmanos do que contra uma guerra contra o terror de fato. 
Beydoun chama a teoria de Huntington, publicada em 1993, de novo orientalismo, já que assim como seus predecessores, o cientista político teoriza em cima de mais de um bilhão de pessoas como se fossem um monólito de malignidade. De acordo com Huntington, o problema não seria o islã radical, mas sim toda a religião, por se tratar de uma civilização diferente e obsessiva com sua falta de poder.

No capítulo quatro, o autor aprofunda o raciocínio a respeito do clash de civilizações demonstrando como a política de Guerra ao Terror foi na realidade uma guerra contra os islamitas. Beydoun recorre à citação do ex-presidente George Bush, a qual ele afirma que sua Guerra ao Terror começava contra a Al-Qaeda, mas não terminava ali, para exemplificar seu pressuposto. Ele inicia sua análise demonstrando como o 11 de setembro e a publicação do Ato Patriótico contribuíram para que o sistema legal americano, se alimentando das estereotipias orientalistas, endossasse a raiva pública contra os muçulmanos e não muçulmanos de pele mais escura (como os sikhs), inaugurando uma nova era de islamofobia estrutural que perpassaria os governos Bush, Obama e Trump.

Segundo o autor, um exemplo dessa islamofobia estrutural foi a proposta de banimento da Sharia, que correu pelos parlamentos de estados como Louisiana, Mississipi e Tennessee, no ano de 2011. Sob a égide de se tratar de uma ideologia totalitária e uma doutrina política militar, políticos do sul tentaram aprovar uma lei que na prática limitaria a confessionalidade islâmica. Beydoun ressalta que essa proposta não só era incorreta do ponto de vista jurídico, visto que a interpretação dessa lei varia de acordo com o entendimento do leitor do islã, como islamofóbica por contrastar com a cláusula pétrea da constituição de livre liberdade de culto.

Um dos filmes que melhor expressa a ideia de guerra entre civilizações e a guerra contra os muçulmanos apresentadas nos capítulos três e quatro, é o filme do político democrata James Webb, Rules of Engagement (2000) [Regras do Jogo]. Na produção, um coronel americano é execrado e processado pelo sistema judiciário dos Estados Unidos por assassinar dezenas de civis iemenitas, porém, com ajuda de um colega do pelotão, ele consegue provar que suas ações foram resultado de um ataque súbito de uma massa raivosa, incluindo mulheres e adolescentes, e acaba inocentado por legitima defesa. Essa revelação deixa implícito ao espectador que o inimigo não seria o fundamentalismo islâmico, mas sim toda a civilização islâmica, incluindo mulheres e crianças, assim como proposto por Huntington sete anos antes.

Vale ressaltar que, conquanto o argumento de Beydoun encontre, mais uma vez, seu equivalente nos filmes hollywoodianos da época, o autor assume, de forma determinista, que o livro de Huntington teve um impacto dominante sobre a política americana da década de 1990, o que não necessariamente é verdade. Ao considerarmos o conjunto de pensadores que impactaram o pensamento conservador nos anos 1980 e 1990, Francis Fukuyama seria o nome mais proeminente, já que foi responsável por formular a doutrina Reagan. 0 trabalho de Huntington aparece em um contexto de transição da política internacional americana e oferece uma alternativa de análise do cenário internacional, após a queda da União Soviética, a partir de uma chave ligada à cultura, conceito praticamente ignorado por Fukuyama em O Fim da História (Browning; Halcli; Webster 2000, 60 - 66).

No capítulo cinco, o autor propõe ao leitor uma reflexão sobre os conceitos de radical e de ameaça imaginada. Beydoun evidencia que a administração Obama foi responsável por direcionar a Guerra ao terror do exterior para os cidadãos muçulmanos que viviam nos Es- 
tados Unidos, fossem imigrantes ou americanos de nascença. Diante da ascensão do Estado islâmico em 2011, o governo Obama criou uma política de contrainteligência, conhecida como CVE (Countering Violent Extremism), que se estruturava nas formas consolidadas de islamofobia, escolhendo os alvos pela fé e não pelo seu histórico criminal. Segundo o autor, essa medida foi extremamente destrutiva para o identitarismo muçulmano, dado que o simples fato de expressar sua confissão por meio da vestimenta ou aparência confere aos islamitas uma imagem negativa associada à perpetração da violência.

No capítulo seis, Beydoun inicia suas considerações apresentando uma citação do muçulmano americano mais famoso da história, Muhammad Ali. No excerto designado pelo autor, o boxeador afirma que enquanto a comunidade negra norte-americana não fosse livre, ele também não seria, ainda que estivesse em uma posição de status e de privilégio financeiro. Ao pautar uma discussão entre racismo e islamofobia, Beydoun reitera que ambas as causas não seguem linhas separadas em decorrência da relação inextricável entre negritude e identidade muçulmana que existe nos Estados Unidos.

Ao tratar do movimento Black Lives Matters, que ganhou força no segundo mandato de Obama (2012 - 2016), Beydoun revela que o grupo mais simpático às pautas dos negros eram os muçulmanos, com $66 \%$ de apoio. Os islamitas eram favoráveis ao movimento que defendia uma reforma política que garantisse à comunidade negra um acesso pleno à cidadania por perceber uma similaridade com a primavera árabe e também em função dos questionamentos sobre a estrutura americana, que, assim como era racista, era também islamofóbica. Cabe destacar ainda uma convergência entre muçulmanos e judeus americanos no que tange a essa causa. Segundo Webb $(2001,24)$, durante a luta pelos direitos civis nos anos 1950 e 1960, os judeus configuraram o grupo confessional que mais apoiou as demandas da população negra, e no caso do movimento de 2014 apareciam em segundo lugar com $57 \%$.

A associação dos negros com o islã não era um fenômeno recente, de acordo com Beydoun. A estrutura do Estado americano foi poucas vezes tão ameaçada quanto pela Nação do Islã (NOI), grupo que reclamava a dignidade afro-americana enfatizando a importância da família, do orgulho racial e do empoderamento da comunidade negra. No entanto, pela visão restrita do Estado americano, ao associar o islã ao Oriente Médio e aos povos árabes, a Nação do Islã foi classificada como um grupo de charlatães. Os ataques à organização eram políticos e raciais e, quando miravam na vertente confessional, o grupo era tratado como um culto à parte.

No último capítulo, Beydoun mais uma vez inicia suas considerações com uma citação, desta vez da poetisa Nayyirah Waheed. Segundo Waheed, os imigrantes haviam partido o oceano ao meio para chegar até ali, apenas para não encontrar ninguém que os quisesse. 0 autor usa esse aforismo para exemplificar ao leitor que seu objetivo nesse capítulo era tratar da política de banimento de muçulmanos iniciada pelo presidente Trump, caracterizada por ele como a "Islamofobia de hoje".

Beydoun dialoga com a obra de James Baldwin, The Fire Next Time, publicada em 1962, durante o Movimento dos Direitos Civis, para exemplificar a batalha contemporânea que os islamitas estavam enfrentando diante da onda de ódio que emergiu durante a campanha presidencial de 2016 e se consolidou com o estabelecimento de uma política para o banimento de muçulmanos. A eleição de Trump significou, de acordo com Beydoun, um momento de transição para a comunidade muçulmana, dado que esse grupo passaria 
a endossar de forma mais expressiva movimentos e pautas progressistas como o combate ao privilégio branco, o feminismo interseccional, a xenofobia e os direitos dos LGBTQs.

Essa aproximação colaborou para que a ideia de islamofobia não ficasse mais restrita à academia ou aos advogados muçulmanos e ganhasse espaço em jornais de grande importância, como o The New York Times, redes sociais e escolas cristãs e judaicas. Esse movimento foi a principal diferença entre os ataques sofridos após o 11 de Setembro e a política de banimento iniciada pelo governo Trump em 2017, visto que após o atentado de 2001 existiu um vácuo na representação dos muçulmanos não brancos.

Em 2017 a situação se deu de forma diferente em função da representação política que os islamitas haviam angariado na última década. Os muçulmanos contavam com a articulação e com a liderança de congressistas democratas, como Ilhan Omar, de Minnessota e André Carson, de Indiana, para confrontar a narrativa política islamofóbica da Casa Branca.

A respeito dessas proposições nos parece um tanto idealizado Beydoun considerar os muçulmanos como um bloco progressista sem levar em conta as nuances da filosofia religiosa promulgada pelo islã e seu contraste com muitas pautas tidas como progressistas. 0 próprio autor evidencia, no capítulo cinco, que no passado os muçulmanos escolheram virar às costas para os muçulmanos negros em sua luta contra o racismo, o que demonstra que o apoio a essas causas não viria de uma forma tão orgânica quanto ele faz parecer. 0 presentismo (Schaff, 1995) aparece de forma evidente mais uma vez, já que Beydoun evidentemente relativiza certos posicionamentos da comunidade islâmica para assegurar uma narrativa favorável.

No epílogo, Beydoun inicia sua conclusão destacando algumas citações, incluindo uma fala de seu pai antes de falecer, em 2016: "Você voltou para casa um pouco antes de eu voltar pra Alá, dele viemos para ele voltaremos." Beydoun encerra seu trabalho citando seu retorno à Detroit, o processo de aceitação da morte de seu pai e a tentativa de sua antiga vizinha de infância de mascarar os traços da identidade muçulmana, após a vitória de Trump, como exemplos da fluidez dos conceitos de lar e imigração.

0 autor reitera que os Estados Unidos eram o país onde os imigrantes muçulmanos haviam escolhido viver com a finalidade de realizar seus sonhos e eles eram capazes de realizá-los, apesar de toda discriminação. Ao votar, marchar e lutar para exercer uma religião demonizada por leis e políticas, os muçulmanos americanos dão vida às liberdades civis que, embora garantidas pela Constituição, lhes foram sistematicamente negadas. Ele encerra a discussão alegando que, assim como eles enterravam seus pais, algum dia eles iriam enterrar definitivamente a islamofobia.

Nos capítulos seis, sete e no epílogo, Beydoun procura fazer uma crítica construtiva à comunidade muçulmana ao evidenciar sua falta de organização e apoio às pautas progressistas, ao mesmo tempo que enxerga de forma positiva o futuro desse grupo identitário após a política de banimento imposta pelo ex-presidente Trump. Hollywood não ficou alheia a uma forte parcela da sociedade americana que rejeitava as políticas de Trump contra os muçulmanos e apresentou novas representações pautadas a partir de uma ótica mais concisa e menos estereotipada pelo imaginário orientalista.

O filme Shaft (2019), por exemplo, apresenta uma visão mais humanizada dos per- 
sonagens muçulmanos e se utiliza do humor para criticar, de forma ácida, os estereótipos presentes no imaginário norte-americano, como quando um dos protagonistas pergunta ao Imã se ele nasceu em um país islâmico ou se se converteu ao islã em uma cela de prisão. A produção tem um plot twist, no qual os personagens muçulmanos, acusados de terrorismo, são inocentados e um dos protagonistas acusa o FBI de racismo e deixa a organização. Essa sequência não só obriga o espectador a questionar os estereótipos, que representam os islamitas como violentos e adeptos de uma causa frívola embasada em concepções frágeis do islã, como também apresenta uma crítica à islamofobia estrutural, promovida por atores estatais.

Nas produções originais das redes de televisão e dos serviços de streaming, outras experiências apresentando personagens muçulmanos sem estereótipos grosseiros e em situações cotidianas também se tornaram populares. Embora em alguns casos o islã se confunda com o secularismo, séries como Legends of Tomorrow, American Gods, Master of None, Superstore, The Blacklist e Counterpart apresentam personagens muçulmanos de forma humanizada, não diferindo tanto de suas contrapartes "ocidentais".

No caso da série Master of None, por exemplo, o protagonista, um indiano muçulmano, está completamente integrado à sociedade americana, porém se vê constantemente em conflito com suas referências religiosas e com a tradição de seu país de origem. 0 programa explora os costumes e as tradições ligados ao islamismo e a Índia, como quando o personagem se sente culpado por gostar de carne de porco ou como quando precisa lidar com um casamento arranjado pela sua família, utilizando a mesma forma das clássicas séries de comédia, ou seja, sem recorrer às caricaturas estabelecidas pelo imaginário.

Por fim, apesar de algumas colocações pontuais em relação ao texto e ao uso do conceito islamofobia pelo autor, fica evidente que Beydoun se embasa em elementos concretos para determinar como a rejeição ao islã estava enraizada no imaginário americano. A análise dos filmes de ficção realizada nessa resenha não só endossa a hipótese do autor sobre a existência de uma islamofobia privada, promovida pelo cinema, mas também demonstra como os americanos entendiam sua identidade como uma construção social fundamentalmente oposta aos muçulmanos. Todavia, a década de 2010 assinalou um aumento da diversidade na indústria cinematográfica, o que contribuiu para que esse imaginário iniciasse um processo de ressignificação.

Beydoun, ao mesclar suas experiências pessoais com autores clássicos e com a história dos Estados Unidos, procura evidenciar como o conceito de entendimento funciona como "uma casa de muitas mansões" (SALIBI, 2005, p.234), não havendo um modelo único para se alcançá-lo. A islamofobia é um fenômeno calcado no orientalismo e seus estereótipos, e tem como principal pretensão não só reafirmar uma política identitária exclusivista para o ocidental, criado como antítese do oriental, mas promover uma suposta superioridade entre os dois modelos. 0 que autor procura evidenciar em cada capítulo é que afirmação identitária muçulmana não significa, necessariamente, um risco aos valores e aos símbolos do imaginário ocidental e, por essa razão, não pode ser associada ao terrorismo e muito menos ser sinônimo dos grupos étnicos do Oriente Médio, excluindo correntes importantes como os negros somalis e os norte-americanos.

\section{Bibliografia}

BACZKO, Bronislaw. Imaginação social. In: Enciclopédia Einaudi. Lisboa: Antropos, 
1985.

BROWNING, Gary; HALCLI, Abigail; WEBSTER, Frank (Edição). Understanding contemporary society. Londres: Sage: Publications, 2000 fel, s/d.

CHARTIER, Roger. A história Cultural: entre práticas e representações. Lisboa: Di-

LAGNY, Michèlle. 0 cinema como fonte de história. IN: Cinematógrafo: Um olhar sobre a História. Salvador : EDUFBA; São Paulo : Ed. da UNESP, 2009.

ROSS, Steven J. Hollywood Left and Right: How Movie Stars Shaped American Politics. USA: Oxford university, 2011

SALIBI, Kamal S. A House of many mansions. The History of Lebanon Reconsidered. Londres e Nova York: I.B. Tauris, 2005

SCHAFF, Adam. História e verdade. Trad. Maria Paula Duarte. 6a ed. São Paulo: Martins Fontes, 1995

WEBB, Clive. Fight Against Fear: Southern Jews and Black Civil Rights. Athens: University of Georgia, 2001 